\title{
САММИТ СОДРУЖЕСТВА НАЦИЙ И НОВАЯ ВНЕШНЕПОЛИТИЧЕСКАЯ СТРАТЕГИЯ БРИТАНИИ
}

\begin{abstract}
Аннотация. 16-20 апреля 2018 г. в Лондоне прошла встреча глав государств Содружества наций. Великобритания как страна-председатель (до 2020 г.) поставила цель провести первый торговый саммит в истории организации. По замыслу Лондона, объединение государств - бывших доминионов, колоний и протекторатов может стать удобным форматом для реализаџии глобальных амбиций Британии на этапе пост-брекзит. Лондон, очевидно, намерен извлечь максимальную выгоду из своего колониального прошлого, задействовать связи со странами Содружества, чтобы продвигать новую внешнюю повестку в рамках концепции «Глобальная Британия». Однако дружественную атмосферу саммита значительно омрачил скандал «Виндраш».
\end{abstract}

Ключевые слова: Великобритания, Содружество наций, саммит, внешняя политика Великобритании пост-Брекзит, скандал «Виндраш».

\section{Саммит 2018 г. - новая повестка}

Полное название министерства иностранных дел Великобритании - Офис по иностранным делам и по делам Содружества (Foreign and Commonwealth Office - FCO). Ещё в 2010 г. глава британской дипломатии У. Хейг отметил, что правительство «вернуло» букву «С» в фокус внимания министерства («we have put the "C" back into FCO») ${ }^{1}$.

В новых условиях, созданных брекзитом, Содружество призвано стать для Британии не только символом британского влияния, но и экономических возможностей за рамками европейской интеграции. Накануне саммита Б. Джонсон в «The Sunday Express» отметил, что идея саммита - «отличная возможность для продвижения «Глобальной Британии» 2 .

В Содружество помимо Британии ходит ещё 52 государства - почти все её бывшие доминионы, колонии и протектораты в Африке, Азии, странах Карибского бассейна и Океании с населением более 2,2 млрд человек (треть всего населения Земли). В большинстве стран Содружества широко распространён английский язык, левостороннее движение, а правовая и политическая система зачастую скопированы с британской.

Содружество - это не торговый и не политический блок, а скорее добровольное объединение - клуб государств, связанных с Великобританией колониальным прошлым. Некоторые из этих стран не всегда соответствуют принятым на Западе стандартам и уровню обеспече-

( Годованюк Кира Анатольевна - кандидат политических наук, старший научный сотрудник Центра британских исследований ИЕ РАН. Адрес: РФ, 125009, Москва, ул. Моховая, д. 11, стр. 3. $\boldsymbol{E}$ mail: kira.godovanyuk@gmail.com

DOI: http://dx.doi.org/10.15211/vestnikieran220186

1 Foreign Secretary's speech, Birmingham 2010. William Hague (Conservative). URL: http://www.britishpolitical speech.org/ speech-archive.htm?speech=345.

${ }^{2}$ Commonwealth has key role to play in the bright future for Britain: article by Boris Johnson. URL: https://www.gov. uk/government/speeches/commonwealth-has-key-role-to-play-in-the-bright-future-for-britain-article-by-boris-johnson. 
ния прав и свобод человека.

Предложение превратить Содружество в союз государств с едиными ценностями привело к подписанию в марте 2013 г. Хартии Содружества, которая провозглашает приоритет демократических принципов и прав человека и запрещает любые формы дискриминации по расовой или национальной принадлежности, политическим убеждениям, полу или вероисповеданию ${ }^{1}$.

Однако в ряде стран Содружества до сих пор действуют дискриминационные законы 20 стран Содружества применяют смертную казнь, а 36 - уголовное наказание за гомосексуализм².

В 2013 г. когда председателем в Содружестве стала Шри-Ланка, Индия и Канада ответили отказом участвовать в саммите, ссылаясь на то, что она не выполняет положения Хартии, систематически нарушает права человека и проводит авторитарную и репрессивную внутреннюю политику.

В 2009 г. к Содружеству присоединилась Руанда, однако две страны покинули объединение - Гамбия (вернулась в состав по итогам саммита в Лондоне в 2018 г.) и Мальдивы. В 2002 г. из-за систематических нарушений прав человека Зимбабве лишили членства в организации (страна официально объявила о выходе из объединения на следующий год).

Готовясь к первой за 20 лет встрече глав государств Содружества в Лондоне (16-20 апреля 2018 г.), Великобритания стремилась провести «лучший саммит», омолодить Содружество, сделав его одной из влиятельных и значительных международных организаций.

Встреча ознаменовала начало двухлетнего периода председательства Великобритании в организации. Лозунгом саммита «В сторону общего будущего» («Towards a common future».) Британия как будто намекает, что у неё не только общее прошлое с этими странами, но и общее будущее. На саммите предполагалось обсудить 4 блока вопросов: продвижение торговли и инвестиций в Содружестве, изменение климата и противодействие природным катастрофам, борьба с угрозами (таким как организованная преступность, кибер-преступность, насильственный экстремизм и торговля людьми), а также продвижение принципов демократии, прав человека, верховенства закона и пр. Заседание проходило в рамках молодёжного, женского, бизнес-форумов, а также форума гражданского общества стран Содружества. По мнению организаторов, эти четыре измерения наиболее полно отражают цели самой организации, как платформы межправительственного, парламентского, профессионального взаимодействия и сотрудничества институтов гражданского общества.

Все меры в конечном итоге были направлены на улучшение имиджа Великобритании в Содружестве и в мире. Лондон всеми силами пытался подчеркнуть, что он - не босс в Содружестве, а один из его членов. Платформа саммита дала Британии возможность укрепить связи с отдельными странами или группами стран. Во внешней политике Великобритании всевозрастающее значение приобретает тихоокеанский регион и, соответственно, такие страны,

\footnotetext{
${ }^{1}$ Charter of the Commonwealth. URL: http://thecommonwealth.org/sites/default/files/page/documents/Charterofthe Common wealth.pdf.

${ }_{2}$ Global Britain and the 2018 Commonwealth Summit. Seventh Report of Session 2017-19. March 2018. URL: https://publications.parliament.uk/pa/cm201719/cmselect/cmfaff/831/831.pdf. P. 11.
}

Научно-аналитический вестник ИЕ РАН, 2018, №2 
как Индия, Канада, Австралия, Новая Зеландия. На саммит, в частности, впервые за долгое время прибыл премьер-министр Индии, который не участвовал во встрече Содружества на Мальте в 2015 г., на Шри Ланке в 2013 г. и в Австралии в 2011 г.

В центре внимания переговоров Т. Мэй и премьер-министра Индии Н. Моди - торговое сотрудничество. Стороны подписали коммерческие соглашения на общую сумму 1 млн ф.ст. Однако Британия рассчитывает на соглашение о свободной торговле с Индией после выхода из ЕС. Вместе с тем, особенно чувствительным остаётся миграционный вопрос. Выходцы из Индии в большинстве своём въезжают на территорию Соединённого Королевства либо по студенческим визам, либо по специальным визам Tier 2 (даёт право находиться и работать в Великобритании квалифицированным иностранным гражданам). Изменения миграционных требований для владельцев студенческих виз негативным образом отразились на индийской диаспоре в Британии. Индия надеется на визовые послабления, в то время как Лондон требует обеспечить выезд граждан Индии, нарушивших миграционное законодательство. Между тем, Меморандум о возвращении нелегальных мигрантов между Британией и Индией истёк ещё в 2014 г. С тех пор стороны ведут переговоры о новом соглашении. В Лондоне Мэй и Моди так и не смогли согласовать этот вопрос и подписать меморандум.

18 апреля 2018 г. в Национальном центре компьютерной безопасности в Лондоне Т. Мэй провела переговоры с лидерами Канады, Австралии и Новой Зеландии, которые наряду с Британией и США входят в альянс разведывательных служб «Пять глаз» ${ }^{1}$. По итогам переговоров Т. Мэй объявила о выделении 15 млн ф.ст. на укрепление кибер-безопасности Содружества: 5,5 млн ф.ст. будут направлены на финансирование мер по противодействию кибер-угрозам в наиболее бедных странах Содружества.

\section{Ошибочная дихотомия EC vs Содружество?}

Саммит полностью соответствует политике диверсификации внешней политики в рамках концепции «Глобальная Британия», хотя решение о встрече глав государств Содружества в Лондоне было принято ещё до референдума о членстве в ЕС. Сегодня в Форин-офис подчёркивают, что Британия расширяла бы сотрудничество со странами Содружества независимо от исхода плебисцита.

25-й саммит стран Содружества должен был состояться в Республике Вануату, однако в 2015 г страна сильно пострадала из-за циклона Пэм, после чего Д. Кэмерон согласился провести саммит Содружества в Великобритании ${ }^{2}$.

Правительство решило воспользоваться представившейся возможностью, чтобы укрепить отношения с бывшими колониям и политическими партнёрами. Отмечалось, что министр международной торговли Л. Фокс планирует встретиться с коллегами более чем из 30

\footnotetext{
${ }^{1}$ The NCSC hosts four Prime Ministers during Commonwealth Summit. URL: https://www.ncsc.gov.uk/news/ncschosts-four-prime-ministers-during-commonwealth-summit.

${ }^{2}$ На Вануату обрушился циклон «Пэм». URL: http://www.bbc.com/russian/international/2015/03/150314_pam_van uaty_cyclone.
} 
стран. Министр по делам Содружества баронесса Патриция Скотланд (уроженка Доминиканы), в свою очередь, отметила, что Великобритания надеется заключить торговые соглашения с 52 членами саммита ${ }^{1}$.

Сегодня в Лондоне осознали, что неконструктивно рассматривать ЕС и Содружество как взаимоисключающие понятия. Как заявила П. Скотланд, Великобритании следует отойти от «ошибочной дихотомии - или ЕС, или Содружество»².

Ещё в 2015 г. появилась информация, что Великобритания решила финансировать специальное контртеррористическое управление в рамках Содружества. На реализацию этой стратегии было решено выделять по 1 млн ф.ст. ежегодно в течение пяти лет. Данное подразделение призвано усилить возможности стран в борьбе с экстремистской идеологией ${ }^{3}$.

Великобритания создала особые условия торговли для наиболее бедных стран Содружества. Некоторые из них получили доступ к рынку Великобритании посредством преференций или соглашения об экономическом партнёрстве с EC (Economic Partnership Agreement). B ряде развивающихся стран Содружества определённые секторы экономики исторически имеют тесные связи с Великобританией. В частности, на британский рынок регулярно поступают бананы из Сент-Люсии, сахар из Фиджи и Белиза, овощи из Кении и говядина из Ботсваны.

Вместе с тем, развивая привилегированное торговое сотрудничество с Британией, эти страны практически впали в зависимость от торговли с Соединённым Королевством ${ }^{4}$. Новые торговые барьеры между ЕС и Великобританией могут поставить под удар поставки из этих стран Содружества. Британское правительство, в свою очередь, пообещало создать аналог торговым соглашениям ЕС для развивающихся стран, заменив собственным торговым подходом схему торговли «Всё, кроме оружия», введённую ЕС в 2014 г. («Everything But Arms») 5.

\section{Некоторые итоги саммита}

Т. Мэй, следуя тактике последних месяцев, стремится максимально задействовать международные площадки для выдвижения на первый план вопросов безопасности и защиты международной системы от нарушений международного права. Неудивительно, что она обратила внимание глав государств Содружества на такие угрозы как «нарушение прав человека режимом Асада, применение химического оружия против мирного населения, а также ис-

\footnotetext{
1 It's a DIAMOND' UK should trade with the Commonwealth post-Brexit, says secretary general. URL: https://www.express.co.uk/news/uk/776744/Commonwealth-UK-Brexit-trade-EU-deal-agreement-diamond.

${ }^{2}$ Priorities for the Commonwealth Secretary-general. House of Lords. The Select Committee on International Relations. 21 July 2016. URL: http://data.parliament.uk/writtenevidence/committeeevidence.svc/evidencedocument/internationalrelations-committee/priorities-for-the-commonwealth-secretarygeneral/oral/35340.pdf p.8.

${ }_{3}$ Великобритания создаст управление Содружества Наций по антитеррору. URL: https://ria.ru/world/20151127/1 330016185.html.

${ }^{4}$ Brexit and Commonwealth Trade. URL: http://thecommonwealth.org/sites/default/files/news-items/documents/Brexit andCommonwealthTrade.pdf. P. 3.

${ }^{5}$ Government pledges to help improve access to UK markets for world's poorest countries post-Brexit. URL: https:// www.gov.uk/government/news/government-pledges-to-help-improve-access-to-uk-markets-for-worlds-poorest-countri es-post-brexit.
} 
пользование нервно-паралитического вещества на улицах Солсбери».

По предложению Великобритании в итоговом коммюнике стра́ны осудили использование химического оружия и подтвердили приверженность укреплению эффективных мер в рамках Конвенции о запрещении химического оружия. В документ, однако, не включили формулировки, осуждающие непосредственно «режим Асада». По сирийскому вопросу в Содружестве наметились серьёзные расхождения. Канада и Австралия недвусмысленно поддержали удары США, Великобритании и Франции по Сирии; Новая Зеландия высказалась уклончиво, отметив, что «всегда отдаёт предпочтение дипломатическим усилиям». Однако большинство стран Содружества не поддерживают действия Британии, более того расценивают их как «империалистический акт» 1 .

Великобритании удалось инициировать межправительственную дискуссию по сотрудничеству в области кибер-безопасности. На итоговой пресс-конференции Т. Мэй подчеркнула, что принятая кибер-декларация Содружества свидетельствует о намерении стран противостоять угрозам, которые подрывают общие ценности, безопасность и демократию2 2

В рамках Декларации предусмотрены совместные действия по борьбе с кибер-преступностью, хакерскими атаками, а также помощь развивающимся странам Содружества в создании собственных систем кибер-безопасности к 2020 г.

Экологическая повестка саммита была зафиксирована в первой Голубой Хартии Содружества. Великобритания, выступая в роли глобального лидера по борьбе с изменением клима та, предложила повестку по борьбе с пластиковым загрязнением океана. Было отмечено, что каждая страна Содружества ратифицировала Парижское соглашение.

Великобритания, подтвердив курс на заключение соглашений о свободной торговле, заручилась поддержкой участников саммита бороться с протекционизмом. В итоге страны приняли Декларацию Содружества о совместной повестке по торговле и инвестициям (Commonwealth Connectivity Agenda for Trade and Investment), призванную увеличить торговый оборот между странами Содружества до 2 трлн долл. США к 2030 г.

Лидеры приняли решение одобрить кандидатуру принца Чарльза как преемника Елизаветы II на посту главы Содружества (титул главы Содружества не передаётся по наследству), несмотря на ранее звучавшие предложения избирать председателя на ротационной основе.

Следующий саммит состоится в Руанде в 2020 г.

\section{Проблема поколения «Виндраш»}

Дружественная атмосфера саммита, между тем, была омрачена так называемым скандалом вокруг поколения «Виндраш», как принято называть тех, кто в период с 1948 по 1971 гг. прибыли в Великобританию из Британской Вест-Индии (страны Карибского бассейна).

\footnotetext{
${ }^{1}$ Smiley Queen met with stone-cold greeting from Theresa May at Commonwealth meeting. URL: https://www. ex press.co.uk/news/royal/948334/Queen-Elizabeth-II-Theresa-May-Commonwealth-leaders-meeting-2018.

2 PM speaks at Commonwealth Press Conference: 20 April 2018. URL: https://www.gov.uk/government/speeches/pmspeaks-at-commonwealth-press-conference-20-april-2018.
}

Научно-аналитический вестник ИЕ РАН, 2018, №2 
Граждане колоний были приглашены заполнить недостающие рабочие места в Соединённом Королевстве после Второй мировой войны. Большую часть трудовых мигрантов в 1948 г. привез лайнер Empire Windrush из Ямайки (отсюда и название целого поколения детей, выросших в Соединённом Королевстве). В Британии тех лет не существовало иммиграционных ограничений для граждан Содружества. Иммигранты считались «freely landed», и им было позволено работать и жить на территории Соединённого Королевства.

Наплыв трудовых мигрантов завершился в 1971 г. с принятием Иммиграционного Акта, ужесточившего законодательство, в том числе для граждан стран Содружества. С 2012 г., согласно новым правилам, для найма на работу, доступа к здравоохранению и другим услугам необходимо предъявлять документы, подтверждающие законность пребывания на территории Британии.

В 2010 г. МВД под руководством Т. Мэй уничтожило все въездные карточки на прибывших с 1948-1971 гг. ${ }^{1}$ В итоге оказалось, что представители поколения «Виндраш», выросшие в Великобритании, не имеют юридических оснований находиться и проживать в Британии. Многим из них грозила депортация, они были лишены доступа к здравоохранению, уволены с работы.

Возмущение общественности вызвал отказ в бесплатном лечении больному раком А. Томпсону. Прожив в Великобритании 44 года, он так и не смог урегулировать свой статус, в связи с чем получил внушительный счёт за медицинское обслуживание - 54 тыс. ф.ст. ${ }^{2}$ Сегодня в Соединённом Королевстве проживает более 500 тыс. человек, которые родились в странах Содружества и прибыли на территорию Британии до 1971 г., 57 тыс. из них не имеют британского гражданства ${ }^{3}$.

Более 160 тыс. человек подписали парламентскую петицию с требованием инициировать миграционную амнистию и выплатить компенсацию людям поколения «Виндраш». Письмо с требованием обеспечить юридический статус для этих людей подписали 140 членов парламента ${ }^{4}$.

Министр внутренних дел Великобритании А. Радд во время дебатов в парламенте 16 апреля 2018 г. официально принесла извинения за случившееся. На саммите Т. Мэй извинилась перед лидерами стран Карибского бассейна, пообещав в кратчайшие сроки разрешить вопрос поколения «Виндраш». Премьер-министр подчеркнула, что рассматривает этих людей как британцев и благодарна за вклад, который они внесли в восстановление Соединённого Королевства после войны.

\section{Выводы}

1. Новая стратегия Великобритании в отношении бывших колоний - попытка в долго-

\footnotetext{
1 Home Office destroyed Windrush landing cards, says ex-staffer. URL: https://www.theguardian.com/uk-news/ 2018/apr/17/home-office-destroyed-windrush-landing-cards-says-ex-staffer.

2 Theresa May refuses to intervene over man’s $£ 54,000$ NHS cancer bill. URL: https://www.theguardian.com/uknews/2018/mar/22/theresa-may-refuses-to-intervene-over-mans-54000-nhs-cancer-bill-albert-thompson.

${ }^{3}$ Commonwealth migrants arriving before 1971, year ending June 2017. URL: http://www.migrationobservatory.ox. ac.uk/commonwealth-migrants-arriving-1971-year-ending-june-2017.

${ }^{4}$ Amnesty for anyone who was a minor that arrived In Britain between 1948 to 1971. URL: https://petition.parliament. uk/petitions/216539.
} 
срочной перспективе продемонстрировать в действии концепцию «Глобальная Британия», за счёт которой страна стремится восстановить свой статус глобального игрока. Учитывая колониальное прошлое, Лондон долгое время воздерживался от заявки на лидерство в Содружестве, поскольку такие действия могли вызвать опасения относительно имперских амбиций Соединённого Королевства. Сегодня Лондон готов активно продвигать повестку Содружества как символ своего влияния в мире. Поиск баланса между лидерством и стремлением не быть «боссом (метрополией), а равным членом» будет продолжаться.

2. Содружество для Великобритании - ещё одна площадка для продвижения амбиций как «глобального полицейского». Лондон активно выдвигает тему безопасности от кибератак, применения химического оружия, используя риторику возросших угроз как дополнительный аргумент для проявления солидарности и сближения с союзниками по различным блокам - ЕС, НАТО и Содружества. Риторика вызовов обязательно сопровождается аллюзиями на угрозу со стороны «ряда стран, нарушающих принципы международного права», про-тив которых, по замыслу Лондона, следует объединять усилия.

3. Сотрудничество Великобритании и стран Содружества в ближайшей перспективе будет реализовано в нескольких направлениях - расширение торгово-инвестиционных связей, гуманитарного сотрудничества, в том числе в рамках программ помощи и более широкого толкования концепции «мягкой силы» как инструмента, способствующего повышению международного влияния. Между тем, 52 страны Содружества имеют разный уровень торгового и культурного взаимодействия с самой Великобританией, поэтому основное внимание Лондона по-прежнему направлено на развитие отношений с такими тяжеловесами объединения, как Индия, Канада, Австралия.

4. Несмотря на заявленную амбициозную повестку, Великобритания пока не выработала полноценную стратегию в отношении Содружества. Более того, правительство не сможет вести открытую и инклюзивную политику в отношении этих стран в условиях ужесточения миграционного законодательства ${ }^{1}$.

\section{Список литературы}

Безбородов Ю.С. Особенности международно-правового статуса Британского содружества. Международное публичное и частное право. №1, 2010.

Заболотный В.М. Мир Британского содружества наций. М., 2010.

Крылова Н.С. Содружество наций: политико-правовые проблемы. М., 1991.

\section{References}

Bezborodov Ju.S. Osobennosti mezhdunarodno-pravovogo statusa Britanskogo sodruzhestva. Mezhdunarodnoe publichnoe i chastnoe pravo. №1, 2010.

Zabolotnyj V.M. Mir Britanskogo sodruzhestva nacij. M., 2010.

Krylova N.S. Sodruzhestvo nacij: politiko-pravovye problemy. M., 1991.

\footnotetext{
${ }^{1}$ См. Подробнее заявление правительства Великобритании. Action on trade and inclusivity to benefit all Commonwealth citizens. URL: https://www.gov.uk/government/news/action-on-trade-and-inclusivity-to-benefit-all-common wealth-citizens.
} 


\section{The Commonwealth Summit and the New UK Foreign Policy Strategy}

Author. Godovanyuk K. Ph.D. in Political Science, Senior Research Fellow at the UK Studies Center, Institute of Europe, Russian academy of Sciences. Address: 11-3, Mokhovaya str., Moscow, Russia, 125009. E-mail: kira.godovanyuk@gmail.com.

Abstract. On April 16-20, 2018 the Summit of Commonwealth took place in London. The UK as presiding country until 2020 intended to host the first trading summit in Commonwealth history. The organization bringing together former colonies, dominions and protectorates of the British Empire will serve as a suitable format to carry out global ambitions of the United Kingdom during the post-Brexit age. London apparently is going to draw benefits from its colonial past and use friendly connections with Commonwealth countries while pursuing the Global Britain agenda. However, amicable environment of the summit was spoiled by the Windrush scandal.

Key words: Britain, Commonwealth, summit, UK Post-Brexit, foreign policy, the «Windrush» scandal.

DOI: http://dx.doi.org/10.15211/vestnikieran220186 